\title{
Ensino Híbrido de Histologia em turmas de INCLUSÃO DE SURDOS
}

\author{
HYBRID TEACHING OF HISTOLOGY IN INCLUSION CLASSES FOR THE DEAF
}

DOI: $10.23926 / \mathrm{RPD} .2526-2149.2020 . v 5 . n 3 . p 1865-1883.1 \mathrm{~d} 863$

\section{Joseane Maria Rachid Martins \\ Mestre em Ensino \\ Profissional - ProfBio \\ (UFPR) \\ jo_rachid@yahoo.com.br}

\section{Mariana da Rocha \\ Piemonte}

Doutora em Bioquímica

(UFPR)

Professora na Universidade

Federal do Paraná (UFPR)

marianapiemonte@gmail.co $\underline{m}$
Resumo: O Ensino de Biologia no Brasil se caracteriza por utilizar uma metodologia predominante expositiva e, somando-se a isso, no caso dos surdos, não há um material didático específico. Então, este estudo objetiva produzir e analisar uma sequência didática de histologia, utilizando a concepção de Ensino Híbrido para surdos, em turmas de inclusão, assumindo essa metodologia como uma contribuição para processo de ensino e aprendizagem dos demais estudantes da classe inclusiva. A metodologia consistiu no desenvolvimento do conteúdo de histologia, utilizando o Ensino Híbrido com atividades investigativas, Objetos Educacionais Digitais (OED): webquest, sway ${ }^{\circledR}$ e kahoot $^{\circledR}$ e autoavaliação. Estavam envolvidos 61 ouvintes e um surdo do $1^{\circ}$ ano do Ensino Médio de um colégio estadual do Paraná. Os estudantes participaram de forma ativa em todas as atividades, e a inclusão de surdos foi colocada em prática viabilizando o acesso a materiais e atividades bilíngues que promoveram a construção de conhecimentos em histologia.

Palavras-chave: Biologia. Ensino Médio. Sequência Didática. Objetos Educacionais Digitais. Tecnologias Digitais de Informação e Comunicação.

\begin{abstract}
Biology teaching in Brazil, is characterized by using a predominantly expository methodology, and, for the deaf students, there is no specific didactic material. So, this study aims to produce and analyze a didactic sequence of histology, using the Hybrid Teaching for deaf people concept in inclusion classes, assuming this methodology, as a contribution to the teaching-learning process for the other inclusive classes students. The methodology consisted of the development of histology content, using Hybrid Teaching with investigative activities, Digital Educational Objects (DEO), webquest, sway ${ }^{\circledR}$ e kahoot ${ }^{\circledR}$ and self-evaluation. One deaf and more 61 listeners students, from the 1st year of high school from a state school in Paraná, were actively involved in all activities, and the deaf inclusion was put into practice enabling access to materials and bilingual activities that promoted the construction of knowledge in histology.

Keywords: Biology. High School. Didactic Sequence. Digital Educational Objects. Digital Information and Communication Technologies.
\end{abstract}




\section{INTRODUÇÃO}

O ensino de Biologia, segundo o documento Orientações Curriculares para o Ensino Médio: Ciências da Natureza, Matemática e suas Tecnologias (BRASIL, 2006), deve possibilitar ao educando a capacidade de discutir temas contemporâneos através de um raciocínio crítico embasado no conhecimento sólido da Biologia. Por isso, a metodologia utilizada deve ser construída de maneira que o processo de ensino e aprendizagem seja efetivo e considere as diferenças individuais.

O estudante deve experimentar uma diversidade de recursos metodológicos, "pois cada situação exige uma solução própria, ou seja, as variações das atividades podem atrair e interessar atendendo as diferenças individuais" (KRASILCHIK, 2008, p. 77). Abreu et al. (2019) destacam que ensinar jovens com deficiência exige um novo olhar sobre a prática pedagógica. Para concretizar tais práticas pedagógicas e atender às peculiaridades dos surdos é preciso considerar que estes fazem parte de uma comunidade, que possuem uma língua própria e uma cultura visuoespacial e, por isso, é fundamental elaborar métodos que considerem esse contexto.

O processo de ensino e aprendizagem dos surdos deve inserir a Libras (Língua Brasileira de Sinais) como a primeira língua e a Língua Portuguesa como a segunda. Subentende-se que o bilinguismo seria uma tendência natural, porém essa proposta vai muito além da língua, possui muitos vieses que necessitam ser analisados. Envolve questões políticas, sociais e culturais, precisa ter um currículo organizado que priorize as habilidades visuais e espaciais dos surdos (QUADROS, 2011). Considerando a escola de inclusão, o bilinguismo na sua essência não se aplica, já que os docentes não são surdos e o ensino depende de intérpretes. Por isso cabe à escola buscar metodologias que contemplem suas necessidades. Para Pereira e Arruda (2017), o material didático, em uma perspectiva bilíngue, dever buscar integrar as duas línguas no processo de construção de sentidos e apreensão dos conceitos, onde ambas se complementem com o apoio da visualidade e das imagens em movimento.

O Ensino Híbrido, também conhecido como blended learning, oferece uma variedade de oportunidades para o ensino e aprendizagem de forma fascinante, pois propõe uma mescla de atividades online e presenciais (BACICH; NETO; TREVISANI, 2015). Por isso, pode ser uma alternativa viável para elaborar planos de aula que combinem as Tecnologias Digitais de Informação e Comunicação (TDIC) com metodologias ativas e investigativas.

Diante desse panorama educacional, o Ensino Híbrido de Biologia em turmas de inclusão torna-se relevante. A produção de uma sequência didática de histologia, utilizando a 
concepção de Ensino Híbrido como metodologia para surdos em turmas de inclusão, e a análise dos benefícios desses para os demais discentes oferecem uma perspectiva promissora para $o$ processo de ensino e aprendizagem que se vislumbra.

\section{ENSINO DE BIOLOGIA E A INCLUSÃO DE SURDOS}

A Base Nacional Comum Curricular - BNCC (BRASIL, 2017), enquanto documento norteador para educação brasileira, destaca que aprender Ciências da Natureza vai além do aprendizado de seus conteúdos conceituais, que é preciso considerar entre outros fatores os processos e práticas de investigação e as linguagens das Ciências da Natureza. Aspectos estes que não se têm conseguido contemplar de acordo com algumas análises da aprendizagem em Ciências.

O Ensino de Biologia já tem por si só inúmeras dificuldades no que tange o processo de ensino e aprendizagem. Os resultados do Programa Internacional de Avaliação de Alunos (PISA, sigla inglesa) elaborados pela Organização para a Cooperação e Desenvolvimento Econômico (OCDE) colocam, em 2018, o Ensino de Ciências do Brasil entre os piores (64 lugar) dos 79 países avaliados (BRASIL, 2019). Ensinar Biologia, considerando a diversidade de estudantes, certamente é um grande desafio, a contar pelo enorme número de crianças e jovens que necessitam de um atendimento diferenciado e um currículo adaptado, conforme preconiza a Lei no 9.394/96 (BRASIL, 1996). Por isso, é necessária uma metodologia adaptada que respeite suas identidades e potencialize suas habilidades.

O professor de Biologia, ao atuar em turmas regulares de inclusão de surdos, precisa entender a importância da língua de sinais e as particularidades que possuem em compreender a Língua Portuguesa escrita. A Lei Federal no $\mathrm{n}^{\circ}$ 10.436, de 24 de abril (BRASIL, 2002), reconhece a Língua Brasileira de Sinais - Libras como língua oficial da comunidade surda, isto é, como primeira Língua, não podendo ser substituída pela Língua Portuguesa. Com isso, os surdos conseguem maior respaldo para buscar um ensino na perspectiva bilíngue que possibilite uma inclusão de fato.

Então, ofertar atividades em uma perspectiva bilíngue, ainda que não seja o contexto bilíngue como propõem os Estudos Surdos, mas que permitam o acesso a um material didático que contemple as habilidades visuais com informações em Libras, imagens (figuras, desenhos e animações) e a participação do surdo com produções na Língua Portuguesa escrita e gravações em Libras podem ser um diferencial. Pereira e Arruda (2017) destacam que para o efetivo acesso ao currículo escolar pelo estudante surdo é necessário garantir, entre outras questões 
pedagógicas e metodológicas, que o material didático utilizado por ele esteja também em Libras, sua primeira língua.

O desempenho dos surdos no Ensino de Ciências, pode ser potencializado com a presença do Intérprete de Libras e de recursos didáticos diferenciados (ROCHA et al., 2015). $\mathrm{O}$ intérprete tem um papel essencial por permitir que a explicação possa ser apresentada em Libras aos alunos (as), suas dúvidas e indagações possam ser socializadas, respeitando sua identidade. Cada estudante, seja ele deficiente ou não, de acordo com Krasilchik (2007), possui origem cultural distinta, visão de mundo diferente, com experiências formais e não-formais, o que exige um currículo que atenda a essas diferenças. $\mathrm{O}$ docente precisa estar atento às características desses estudantes para criar e/ou adaptar seus métodos, visando o envolvimento de cada um de seus discentes, observando detalhadamente suas peculiaridades.

\section{ENSINO Híbrido: UMA PERSPECTIVA VIÁvel}

O Ensino Híbrido conduz o estudante ao desenvolvimento de autonomia e disciplina, viabilizando uma maior flexibilização no acesso às atividades, e ao mesmo tempo, uma interação com o grupo nos momentos presenciais. Além disso, pode-se inserir o Ensino por Investigação nesse contexto, em que o professor propõe situações-problema de modo que representem um desafio, promovendo o processo ativo na construção da aprendizagem de conceitos e procedimentos da ciência (TRIVELATO; TONIDANDEl, 2015). Com isso, abre possibilidade de aliar uma gama diversa de recursos relacionados à aprendizagem, oportunizando que cada um aproveite mais os momentos online e presenciais (SPINARDI; BOTH, 2018).

A proposta pedagógica do Ensino Híbrido pode trazer às escolas regulares com alunos de inclusão, como os surdos, uma metodologia que oportuniza entrar em contato previamente com o conteúdo e com um material específico, dessa maneira o professor terá possibilidade de explorar abordagens distintas e estimular os estudantes a contribuírem com o debate (ROTHSTEIN; SANTOS, 2017). Isso requer do docente uma organização metodológica de modo a promover a acessibilidade ao material por meio das TDIC, o que permite a análise do conteúdo sob vários aspectos, fazendo uso de diferentes formatos de mídias.

As TDIC, além de despertarem o interesse, contribuem significativamente para compreensão de processos e fenômenos científicos, já que disponibilizam representações diversas (MARTINHO; POMBO, 2009). As experiências visuais que podem ser utilizadas nas 
práticas pedagógicas em Biologia contribuem com a construção do conhecimento dos surdos, visto que têm a capacidade visomotora bem desenvolvida.

Os Objetos Educacionais Digitais (OED), conforme destaca Mercado, Silva e Gracindo (2008), são de extrema relevância na educação, pois os jovens têm cada vez mais acesso às TDIC, sendo inevitável que docentes e discentes estejam mais integrados. Com isso, variados OED têm sido ofertados, como simuladores, jogos digitais, blogs e aplicativos (FIGUEIREDO et al., 2011; FERREIRA; PEREIRA, 2013; LOPES; LOPES, 2017; VASCONCELLOS; MELANI, 2017; ALCÂNTARA; MORAES FILHO, 2015). Há relatos positivos no uso de OED também na inclusão de surdos (BECKER et al., 2014; SCHIMIGUEL; FERNANDES; FRANÇA, 2014).

Nessa perspectiva, é viável utilizar OED onde vídeos em Libras possam ser inseridos, assim como legendas (devido à dificuldade dos surdos com a língua portuguesa) e/ou imagens para ensinar Biologia. Também seria importante que todos os educandos de classes inclusivas pudessem ser protagonistas nesse processo, usando alguns desses recursos para produzir trabalhos temáticos em Biologia. Assim, abre-se a possibilidade para que o surdo possa explicar na sua língua conceitos orientados pelo professor e o material possa ser compartilhado através dos OED com os demais colegas.

Compondo a metodologia do Ensino Híbrido estão as práticas em laboratório, aulas que vêm se mostrando um importante recurso didático no ensino de Ciências e Biologia nas escolas de Educação Básica, conforme destacam Silva et al. (2015). As aulas práticas contribuem com a melhoria no processo de ensino e aprendizagem do conteúdo teórico e ainda, quando construídas dentro de uma visão investigativa, oportunizam aos discentes uma análise com conclusões relevantes sobre os temas estudados (KRASILCHIK, 2008).

\section{COMO FOI FEITO: PERCURSO METODOLÓGICO}

A proposta metodológica consistiu no desenvolvimento do conteúdo de histologia numa perspectiva bilíngue para surdos em classe de inclusão, utilizando o Ensino Híbrido com atividades investigativas e os OED webquest, sway ${ }^{\circledR} e$ kahoot ${ }^{\circledR}$, além de uma autoavaliação. Estavam envolvidos o professor de Biologia, a intérprete de Libras, 61 estudantes ouvintes e um surdo do $1^{\circ}$ ano do Ensino Médio matutino das turmas A e B de um colégio estadual do munícipio de Pinhais, no Paraná.

Os pais e/ou responsável legal dos estudantes receberam todas as informações sobre as atividades. O trabalho em questão foi submetido à apreciação e aprovação da SEED (Secretaria 
Estadual de Educação do Paraná), e ao Comitê de Ética em Pesquisa da Universidade Federal do Paraná (CEP/UFPR) Parecer n 3.540.358, conforme resolução do Conselho Nacional de Ética em Pesquisa, obtendo a aprovação em todos os quesitos.

O Quadro 1 apresenta as atividades aplicadas.

Quadro 1 - Atividades aplicadas

\begin{tabular}{|c|c|c|}
\hline Atividade & Proposta & Objetivo \\
\hline 1. Webquest & $\begin{array}{l}\text { Produção de um material com viés bilíngue, com } \\
\text { vídeos baseados em material previamente } \\
\text { produzidos na forma de textos e imagens. }\end{array}$ & $\begin{array}{l}\text { Auxiliar os estudantes a } \\
\text { compreender cada atividade } \\
\text { - Roteiro de pesquisa. }\end{array}$ \\
\hline $\begin{array}{l}\text { 2. Investigação } \\
\text { histológica }\end{array}$ & $\begin{array}{l}\text { Descoberta dos tecidos fundamentais e suas } \\
\text { variantes (tecido epitelial, conjuntivo } \\
\text { propriamente dito, adiposo, cartilaginoso, ósseo, } \\
\text { hematopoiético, muscular e nervoso) através de } \\
\text { pistas cm código QR. }\end{array}$ & $\begin{array}{l}\text { Descobrir o tecido } \\
\text { correspondente às pistas } \\
\text { com suas características. }\end{array}$ \\
\hline 3. Prática em laboratório & $\begin{array}{l}\text { Dissecção de coxa e sobrecoxa de galinha para } \\
\text { correlação macro e microscópica através de } \\
\text { cartões histológico (Figura1), cartões contendo } \\
\text { imagens de cortes histológicos (PIEMONTE et al, } \\
\text { 2019) }\end{array}$ & $\begin{array}{l}\text { Identificar os principais } \\
\text { tecidos animais. }\end{array}$ \\
\hline 4. Construção sway® & $\begin{array}{l}\text { Criação de um sway® de histologia por turma } \\
\text { para que cada equipe iniciasse uma seção } \\
\text { referente o tecido que descobriram na atividade } \\
\text { de investigação histológica. }\end{array}$ & $\begin{array}{l}\text { Identificar e caracterizar os } \\
\text { principais tecidos animais. }\end{array}$ \\
\hline 5. Jogo kahoot ${ }^{\circledR}$ & $\begin{array}{l}\text { Participação em um jogo digital de perguntas e } \\
\text { respostas (Figura 2) sobre os tecidos. }\end{array}$ & $\begin{array}{l}\text { Reconhecer as principais } \\
\text { características dos tecidos } \\
\text { animais. }\end{array}$ \\
\hline 6. Autoavaliação & $\begin{array}{l}\text { Avaliação da participação e aprendizagem em } \\
\text { cada atividade, com sugestões e críticas. } 3 \text { a nota } \\
\text { máxima para o quesito avaliado, zero a nota } \\
\text { mínima e } 1 \text { e } 2 \text { as notas intermediárias }\end{array}$ & $\begin{array}{l}\text { Fazer uma autoanálise em } \\
\text { relação à participação e } \\
\text { aprendizagem. }\end{array}$ \\
\hline
\end{tabular}

Figura 1 - Cartões histológicos

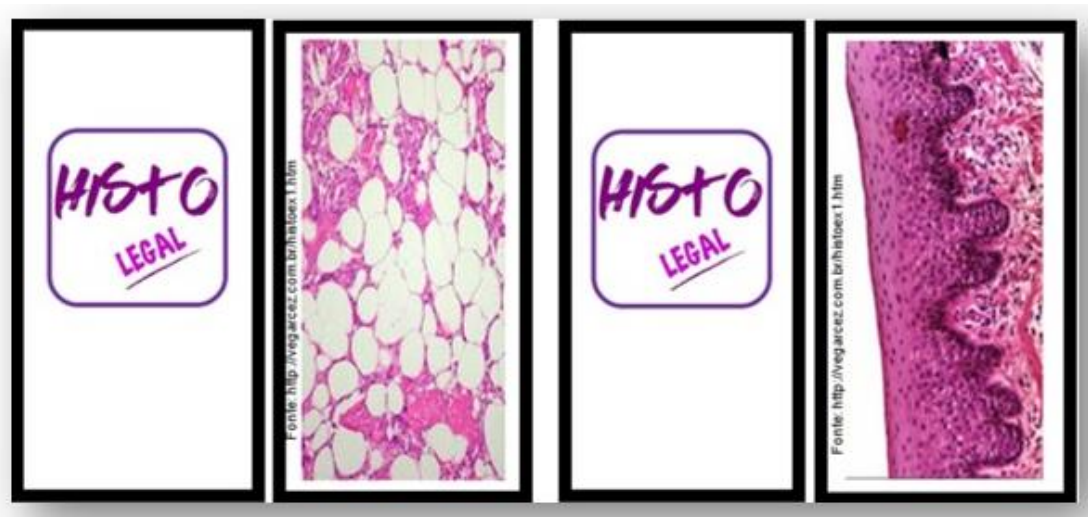

Fonte: A autora (2019). 
Figura 2 - Questões Kahoot ${ }^{\circledR}$

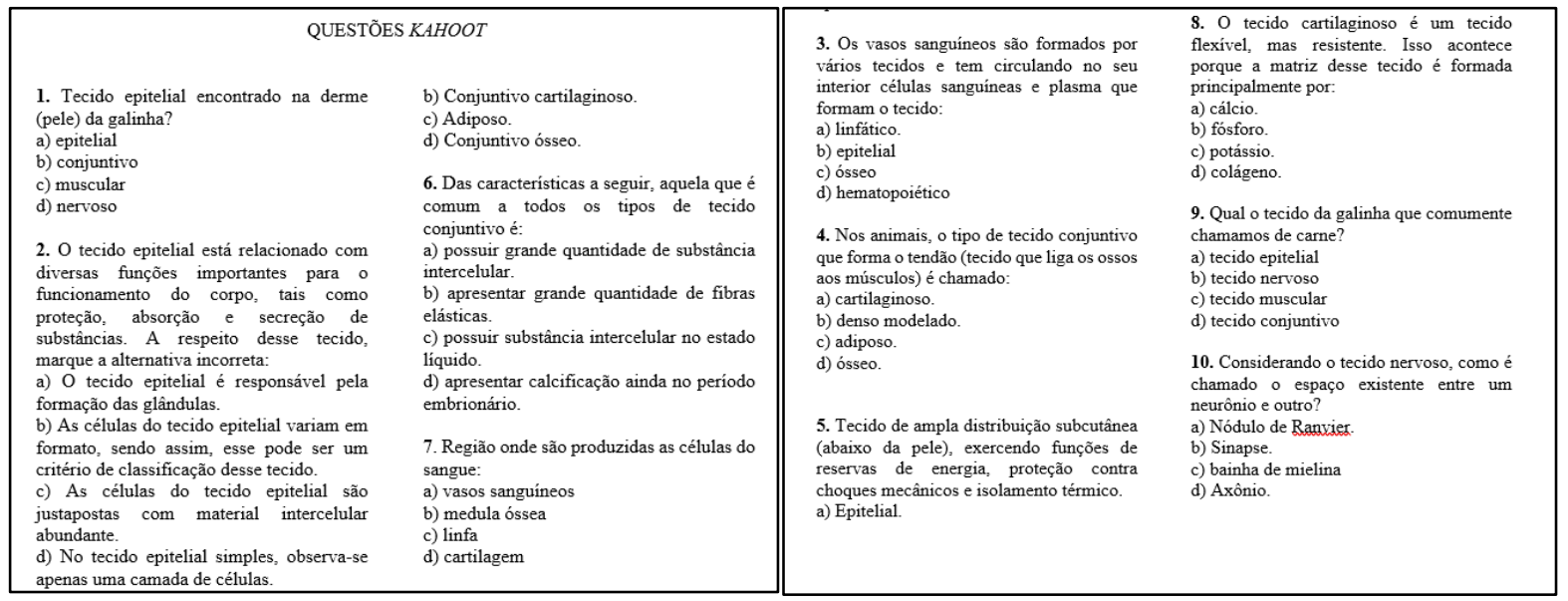

Fonte: A autora (2019).

Schneider, Fujii e Corazza (2017) afirmam que a pesquisa qualitativa pode ser apoiada pela pesquisa quantitativa e vice-versa, possibilitando uma análise estrutural do fenômeno com métodos quantitativos e uma análise processual mediante métodos qualitativos. Nesse trabalho, a análise quantitativa não foi realizada a título de comparação entre grupos, mas para mensurar dificuldades dos estudantes que exigiam a retomada de conteúdos e/ou uma adequação metodológica. Tal análise foi realizada a partir das observações da dinâmica em sala de aula e participação dos educandos antes, durante e após a participação nas atividades. Para a análise quantitativa foram utilizados os dados das questões do kahoot ${ }^{\circledR}$.

\section{WEBQUEST: UM ROTEIRO BILÍNGUE DAS ATIVIDADES DE HISTOLOGIA}

A $1^{\text {a }}$ etapa da atividade foi a construção da webquest utilizando a plataforma Wix® onde todas as informações em português foram traduzidas em vídeos em Libras. A webquest de histologia foi denominada Histo Legal $^{1}$ e foi dividida em apresentação, introdução, tarefas, processo, avaliação, conclusão e créditos. Em cada um desses ícones foram colocadas informações em português, imagens e vídeos e Libras.

A $2^{\mathrm{a}}$ etapa gerou grande interesse, pois os estudantes puderam ter o primeiro contato com o conteúdo de histologia e com as atividades que se seguiram, ou seja, tinham agora um material didático bilíngue que serviu de apoio para a realização das tarefas propostas. Esse interesse dos jovens pela tecnologia já é inerente a sua natureza, cabe à escola e aos educadores se apropriarem dessas ferramentas tecnológicas para fins educacionais. Ademais, quando o docente propõe aos discentes atividades por meio das tecnologias, está estimulando e

\footnotetext{
${ }^{1}$ Disponível em:< https://jorachid.wixsite.com/histolegal > Acesso em 14 mar. 2020.
} 
facilitando a relação com a cognição, que pode levar ao conhecimento vivenciado (GENEROSO et al., 2013).

O estudante surdo mostrou-se muito surpreso ao ver os vídeos em Libras com sua intérprete e lembrou que o material vai ajudar os colegas surdos que chegarão ao $1^{\circ}$ ano, já que não possuem um material didático específico. Segundo observações sistemáticas realizadas pelas autoras deste estudo, os surdos chegam ao $1^{\circ}$ ano do ensino médio com dificuldades para compreender o conteúdo no livro didático, ou em qualquer material escrito, o que corrobora as observações de Peixoto (2006) que destacam os entraves em relação à produção e interpretação com a Língua Portuguesa.

A inclusão dos surdos em classes regulares tem o respaldo legal nos documentos oficiais, começando pela Constituição Federal (BRASIL, 1988), a Lei de Diretrizes e Bases Nº 9. 394/96 (BRASIL, 1996), bem como em outros documentos produzidos pelos Ministério da Educação (MEC). Entretanto, o surdo ainda não encontra a Libras como primeira língua e conteúdos com metodologias adaptadas ou adequadas para que a inclusão possa atender às leis. Uma metodologia que privilegie a língua de sinais pode minimizar as dificuldades que enfrentam em seu cotidiano escolar. Assim, um material como a webquest, com vídeo em Libras certamente proporciona ao surdo uma melhor percepção de fenômenos biológicos contemplando suas necessidades e privilegiando suas habilidades visuais

\section{INVESTIGAÇÃO HISTOLÓGICA - DESCOBERTA DAS PISTAS}

A atividade com código QR suscitou motivação e curiosidade, a aula se tornou mais atrativa e o conteúdo mais significativo para educandos do primeiro ano do Ensino Médio. Stylianoudakis e Bôaventura (2018) destacam que o uso de códigos QR, baseado no conceito do mobile learning, pode dar um novo enfoque aos processos de ensino e aprendizagem, inserindo uma nova dinâmica que pode motivar os educandos. A criação de códigos QR pode ser uma interessante estratégia de ensino e de aprendizagem, cujos objetivos podem ser a produção e socialização de materiais, o desenvolvimento da autoria, da autonomia e do trabalho colaborativo. (NICHELE; SCHLEMMER; RAMOS 2015).

Essa atividade também promove o Ensino por Investigação, conforme conceituam Trivelato e Tonidandel (2015), pois o professor é o orientador da investigação, instiga a formulação de hipóteses, viabiliza a pesquisa de informações, auxilia as discussões e orienta atividades nas quais os estudantes reconhecem as razões de seus procedimentos. O que se 
propôs foi a construção de habilidades cognitivas a partir de uma atividade científica, e não a memorização de conceitos, corroborando as ideias de Solino, Ferraz e Sasseron (2015).

A utilização do celular com o aplicativo para leitura dos códigos QR (Figura 3) chamou a atenção do estudante surdo, pois trouxe a ludicidade para atividade. Para Fonseca et al. (2014) o uso dos recursos tecnológicos ajuda o educando a conhecer também diferentes maneiras de aprender, como é o caso do aprendizado com recursos lúdicos e o aprendizado de conteúdos por meio de busca, participação e interação com uso das TDIC.

Figura 3 - Cartela com código QR e respectiva pista
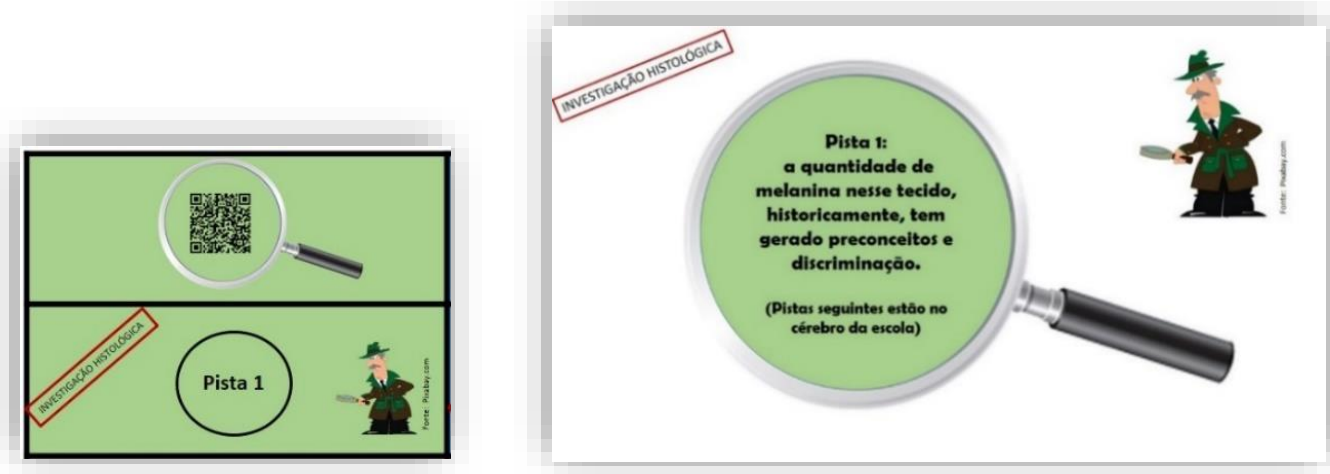

Fonte: A autora (2019).

\section{IDENTIFICAÇÃO DOS TECIDOS EM LABORATÓRIO}

A proposta teve uma excelente receptividade, a curiosidade e a euforia ficaram evidentes logo que os estudantes souberam da atividade, inúmeros questionamentos e dúvidas foram lançados sobre a tão esperada aula. Eles assumiram desafio de encontrar os tecidos no material biológico como uma investigação divertida, por isso pesquisaram no livro didático características, comparavam com as fichas histológicas e preocupavam-se em fotografar corretamente. Tal proposta corrobora Soares e Baiotto (2015) que destacam a importância da atividade experimental como uma atividade com fundamentação investigativa. De fato, a proposta não se resumiu a mera observação ou a manipulação de vidrarias, teve um enfoque científico que possibilitou ao estudante ser um agente ativo em todo processo de construção do seu entendimento.

Posteriormente, conforme orientação, fizeram um relatório com as fotos tiradas do material biológico e com os cartões histológicos. Os relatórios seguiram as instruções solicitadas, todos postaram o material, apesar de algumas equipes terem confundido alguns tecidos com o cartão histológico correspondente, o que já era esperado, considerando que 
precisaram fazer pesquisa e comparação. Após a postagem, o docente fez os apontamentos pertinentes, bem como as correções necessárias. O que se espera é justamente que, além de estimular o interesse, as aulas práticas possibilitem que aprendam conceitos e desenvolvam habilidades de investigação (KRASILCHIK, 2008).

As observações feitas durante a aula em relação ao surdo revelaram uma boa interação com os colegas e grande empenho em procurar os tecidos na coxa e perna de galinha, além de estímulo para relacionar com o cartão histológico correspondente (Figura 10). Roald (2002) recomenda, entre outras coisas, a realização de experimentação didática em sala de aula e a utilização de relatórios de aula prática para facilitar a compreensão do conteúdo proposto pelos educandos surdos.

\section{SWAY® - UMA CONSTRUÇÃO COLABORATIVA}

O sway® sendo uma wiki já traz em si o conceito de colaboração. Conforme Ramos, Santos e Anastácio (2019) uma wiki origina novas formas de colaboração no trabalho escolar, transformando as práticas educativas cotidianas, na perspectiva da coautoria dialógicoproblematizadora. A construção do sway® foi iniciada no laboratório de informática da escola, onde cada equipe acessou o link do sway® de sua turma, disponibilizado na sala virtual, e iniciou o trabalho. As equipes pesquisaram na web (nos links colocados na webquest) e no livro didático, preocupando-se em buscar informações corretas, bem como em inserir todas as referências utilizadas no texto, nas imagens e vídeos. Dois sways ${ }^{\circledR}{ }^{2}$ foram criados e cada equipe produziu uma seção referente o tecido descoberto na atividade 1. Então, cada grupo foi construindo uma sway ${ }^{\circledR}$ sobre histologia de forma colaborativa, acessando a mesma plataforma. E à medida que iam construindo a página, o professor fazia a mediação do processo através de correções e apontamentos necessários.

Neste instante de criação e elaboração, o educando busca a superação das dificuldades e problemas que vão surgindo durante o processo, assim estes permanecem em contato com diversos conhecimentos possíveis de serem assimilados (GENEROSO et al., 2013). A maioria das equipes focou em criar seções com imagens, colocar vídeos com legendas e fotos da aula

\footnotetext{
${ }^{2}$ Sway turma A disponível em: https://sway.office.com/3miYnXmrBaTFf9SG?ref=Link\&loc=play. Acesso em 15 mar. 2020. Sway turma B disponível em: https://sway.office.com/Fx8pyNhH3RFjJRpI?ref=Link\&loc=play. Acesso em 15 mar. 2020.
} 
prática. Uma das equipes encontrou um vídeo na web com legenda em Libras e o inseriu em uma das seções.

O estudante surdo colocou na seção do seu grupo um vídeo em Libras produzido por ele e também colocou algumas informações em língua portuguesa escrita, como: "Tecido adiposo: o que como tecido esta gordo pessoas depende com vivem de mais energia corpo humano a causar." Segundo Fernandes (2012) na avaliação escrita dos surdos deve-se considerar que a produção está organizada em segunda língua, e não na língua materna, por isso é fundamental valorizar o conteúdo desenvolvido pelo estudante, buscando a coerência em seu texto, mesmo que a estruturação da frase não corresponda aos padrões exigidos para nível/série em que se encontra. Fernandes (2012) alerta ainda que, é comum o texto do surdo ter troca de artigos; omissão ou erros no uso de preposições, conjunções; problemas de concordância nominal, alterações atípicas na ordem sujeito-verbo-objeto, entre outros "erros", como de fato foi observado nas frases produzidos pelo aluno.

\section{9 КАНООT ${ }^{\circledR}$ - JOGO DE HISTOLOGIA}

Os discentes demonstraram surpresa diante do kahoot ${ }^{\circledR}$, somente alguns já conheciam o jogo, havendo grande interesse e vontade de acertar as questões apresentadas. Quando cada questão aparecia no datashow, todos silenciavam para ler e rapidamente apertar o botão correspondente à resposta (Figura 4). Por meio desse aplicativo, é possível aumentar o interesse dos jovens para a aprendizagem e melhorar as práticas pedagógicas (JÚNIOR, 2017).

Figura 4 - Estudante respondendo uma questão do kahoot $®$

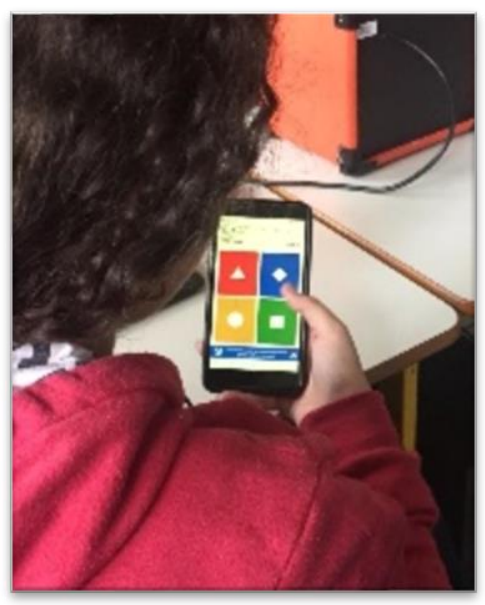

Fonte: A autora (2019).

A cada questão projetada, uma música acompanhava a contagem regressiva para clicar na resposta, gerando grande atenção para acertar rapidamente a resposta. Para Silva et al. 
(2018)), o kahoot ${ }^{\circledR}$ contribui para a gamificação na sala de aula por apresentar elementos de games (jogos), como estabelecer regras, retorno imediatos, pontuação por acerto, competição entre alunos/equipes, além de proporcionar muita diversão durante o processo de ensino e aprendizagem.

Os estudantes da turma A acertaram 50\% das questões e os da turma B, 47\% (Figura 5). Importante destacar que a amostra é pequena, o ideal seria uma amostra maior (mais turmas) para dados mais conclusivos. Ademais, o kahoot ${ }^{\circledR}$ propõe um jogo de competição com cronômetro de contagem regressiva, onde os mais rápidos vão ficando nos primeiros lugares do ranking de cada questão, isso certamente dificultou a análise das questões e por consequência levou a muitos erros. Dessa forma, não seria coerente analisar os dados para tirar conclusões acerca da eficácia de toda uma sequência didática como a aqui aplicada.

Segundo Luckesi (2003), deve-se analisar o processo de avaliação como uma ferramenta diagnóstica, como um recurso de acompanhamento e reorientação da aprendizagem, ao invés de ser um mero recurso classificatório. Por isso, os dados obtidos não devem ser usados como única forma de análise do aprendizado para o conteúdo trabalhado, pois uma atividade com 10 questões objetivas não pode mensurar o processo de ensino e aprendizagem como um todo.

É possível fazer alguns apontamentos relevantes, como nas questões 1 e 8 , que mostraram um maior número de acertos em relação às demais questões em ambas as turmas (Figura 5), que eram questões mais relacionadas à aula prática. Já a questão 4 parece ter sido difícil (Figura 5), porque a classificação do tecido conjuntivo propriamente dito não foi bem compreendida, nenhuma alternativa se mostrou muito clara quanto ao tipo de tecido, confundindo os estudantes. O professor deve utilizar suas ferramentas avaliativas para perceber que a natureza do erro pode não só estar relacionada com a compreensão de um processo, mas com a própria avaliação em si (FREITAS; NINKE; MIGUEL, 2018). Se faz necessário um olhar neutro para todo o processo de ensino e aprendizagem, pois segundo Hoffman (2014) a avaliação é essencial e inerente à educação, por isso precisa ter um caráter problematizador, gerando questionamento e reflexão sobre a ação. 
Figura 5 - Kahoot - Turma A x Turma B

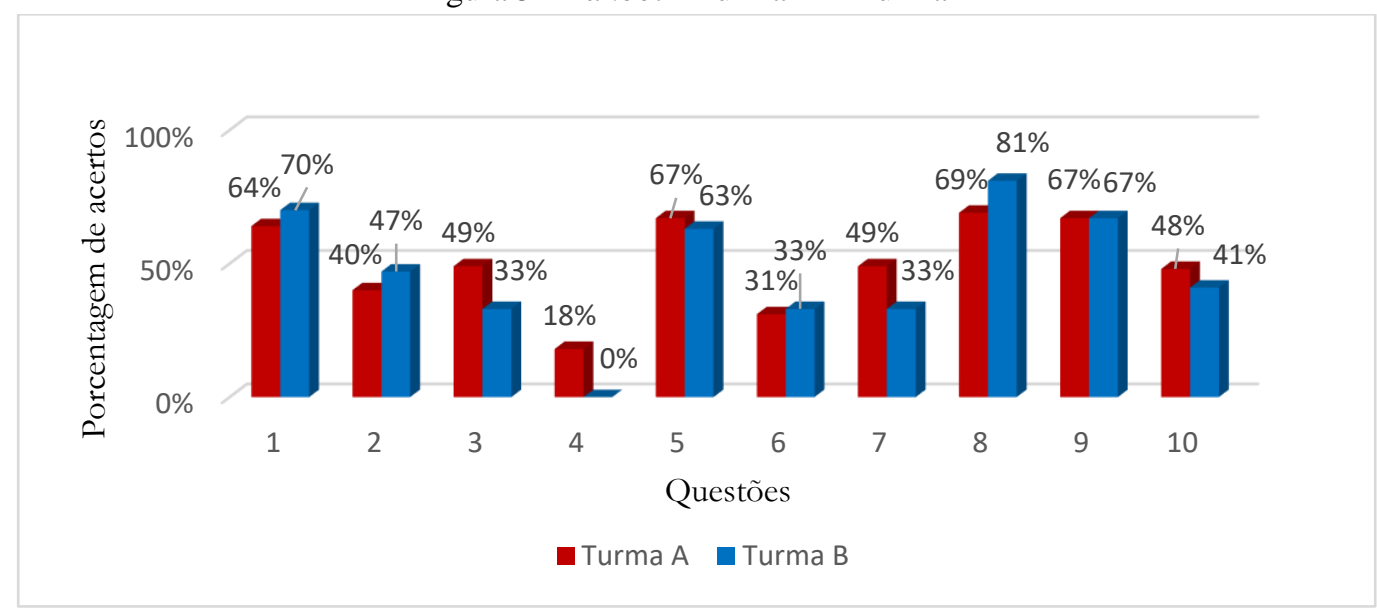

Fonte: A autora (2019)

Júnior (2017) percebeu em seu trabalho que o kahoot ${ }^{\circledR}$ também pode ser convertido em uma ferramenta de inclusão, pois ele permite a inserção de imagens, vídeos e sons no local da pergunta. Foi exatamente o que foi feito, para que o surdo pudesse compreender melhor foram utilizadas imagens e vídeos curtos em algumas questões. Ele teve também o auxílio da intérprete de Libras para responder às questões, não demonstrando muita dificuldade na compreensão.

\section{AutoavaliaÇÃo - UMA REFLEX̃̃o NECESSÁRIA}

A autoavaliação é um exercício importante para os educandos. Conforme Almeida e Fernandes (2016) esse instrumento é útil para a reflexão da prática docente, estimula a autonomia do discente, proporciona a liberdade de expressão e o sentimento de pertencimento ao processo de ensino e aprendizagem.

Os estudantes, por não estarem habituados a realizarem uma autoavaliação, demonstraram um pouco de dificuldade, porém os dados revelam que cerca de $80 \%$ se interessaram mais pelas atividades com código QR, a aula prática e o jogo kahoot@ (Figura 6). Em relação a aprendizagem, $74 \%$ afirmaram terem melhor desempenho na aula prática (Figura 7). Ao comparar os dois gráficos é possível notar que no kahoot ${ }^{\circledR}$ o interesse relatado foi maior (Figura 6) que a aprendizagem que afirmam terem tido (Figura 7), o que provavelmente se deve à dinâmica do jogo, que exige conhecimento e agilidade ao responder, o que teria culminado em um desempenho abaixo do que os alunos desejavam. O sway® apresentou valores baixos para os dois gráficos, o que evidencia o desinteresse em pesquisar, em selecionar vídeos e imagens referentes ao respectivo tecido. Também se deve considerar que tal atividade pode não 
ter sido tão interessante diante da oferta de atividades mais dinâmicas, mas certamente se somou para contribuir com a construção do conhecimento em histologia.

Figura 6 - Autoavaliação do interesse em cada atividade 3 a nota máxima para o quesito avaliado, zero a nota mínima e 1 e 2 as notas intermediárias

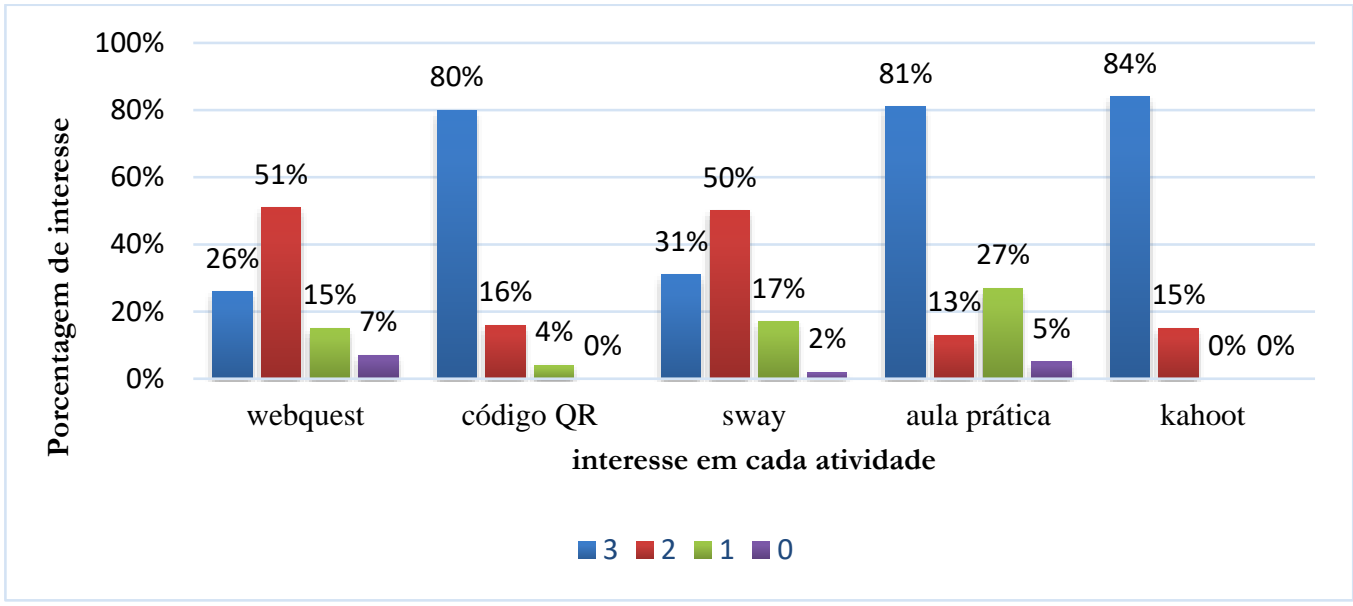

Fonte: A autora (2019).

Figura 7 - Autoavaliação da aprendizagem em cada atividade 3 a nota máxima para o quesito avaliado, zero a nota mínima e 1 e 2 as notas intermediárias

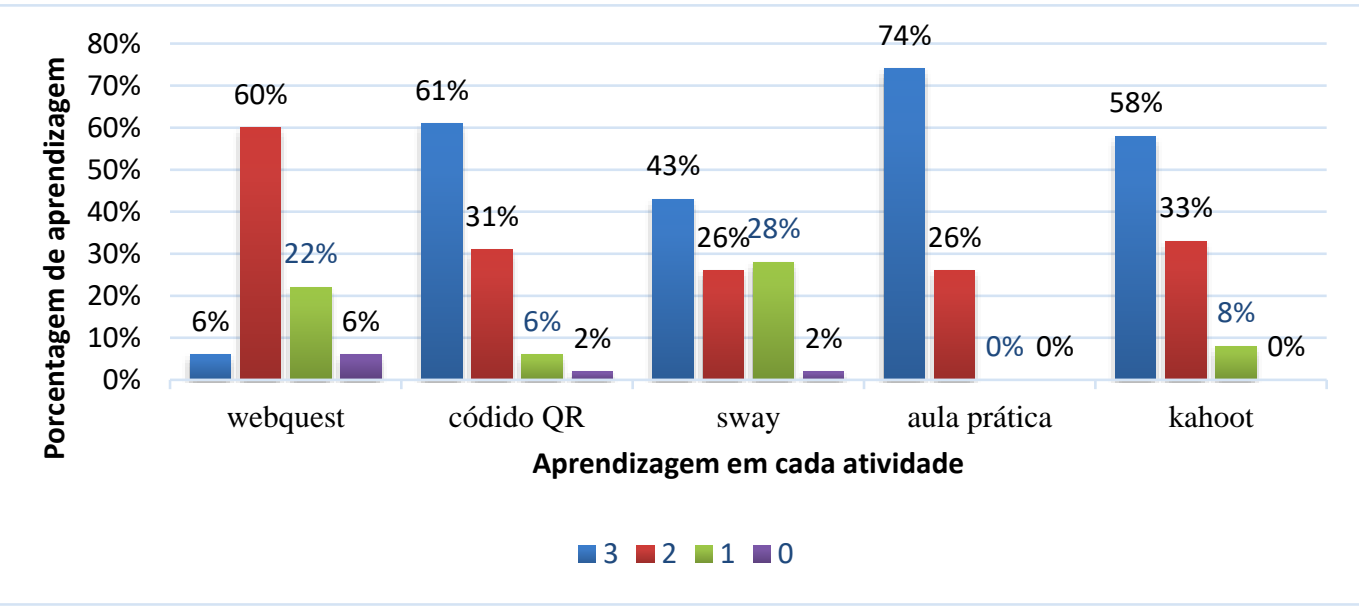

Fonte: a autora (2019)

Segundo o quadro de sugestões de atividades, a maioria dos estudantes considerou as atividades como sendo excelentes, visto que poucas foram as sugestões. O surdo escreveu nas sugestões que achou muito legal a acessibilidade da webquest com os vídeos em Libras e que aprendeu bastante. Também disse que no último bimestre aprendeu mais com a aula prática, o jogo, mas que teve dificuldade com algumas palavras em português.

A análise desses dados juntamente com os das demais atividades são importantes para que o docente possa reavaliar sua metodologia e propor readequações para aplicação da sequência didática em outras turmas. A autoavaliação dos discentes permite que o docente analise sua prática, percebendo qual metodologia se adequa a sua prática, e também oferece 
oportunidade para que esses exponham livremente suas opiniões, sinalizando aspectos metodológicos que precisam ser repensados pelo professor (ALMEIDA e FERNANDES, 2016).

\section{CONSIDERAÇões FINAIS}

O estudo mostrou que a sequência didática de histologia utilizando a concepção de Ensino Híbrido para surdos em turmas de inclusão contribuiu para processo de ensino e aprendizagem dos ouvintes e do surdo da classe inclusiva de Biologia.

A sequência didática não só proporcionou a inclusão do estudante surdo através de um material bilíngue, mas vai possibilitar que todos os surdos que cheguem ao ensino médio possam usufruir desta proposta didático-metodológica já adaptada e disponível. A metodologia utilizada coloca em prática a inclusão de surdos viabilizando o acesso a materiais e atividades que promovem a construção de conhecimentos para esses alunos.

A análise dos resultados permite afirmar que o educando surdo e os ouvintes foram capazes de construir seus conhecimentos na disciplina de Biologia de forma ativa, por meio de atividades com pistas em código QR, pesquisa com webquest, apresentação no sway ${ }^{\circledR}$, aula prática com coxa e sobrecoxa de galinha e questões no kahoot ${ }^{\circledR}$. As atividades propiciaram o protagonismo dos estudantes melhorando, a prática docente no $1^{\circ}$ ano do Ensino Médio.

Sendo assim, o Ensino Híbrido de histologia em turmas de inclusão de surdos pode ser utilizado e/ou adaptado às diferentes realidades e até mesmo a conteúdos distintos pelos educadores em suas práticas pedagógicas.

\section{REFERÊNCIAS}

ABREU, Cremilda Peres Cangussu de; RABELO, Lucélia Cardoso Cavalcante; SOUZA Henrique Silva de; FARIA, Maria José Costa; SOARES, Narciso das Neves. Ensino de biologia para alunos surdos de uma escola pública: desafios na prática docente e da formação continuada. Revista Prática Docente, v. 4, n. 2, p. 697-712, 27 dez. 2019. Disponível em: http://periodicos.cfs.ifmt.edu.br/periodicos/index.php/rpd/article/view/541. Acesso em: 10 set. 2020.

ALCÂNTARA, Nayra Rodrigues; MORAES FILHO, Aroldo Vieira de. Elaboração e utilização de um aplicativo como ferramenta no ensino de Bioquímica: carboidratos, lipídios, proteínas e ácidos nucleicos. Revista de Ensino de Bioquímica, v. 13, n. 3, p. 54-72, 2015. Disponível em: http://bioquimica.org.br/revista/ojs/index.php/REB/article/view/560/518. Acesso em: 20 ago. 2020. 
ALMEIDA, Vanessa Alves Cruz de; FERNANDES, Hylio Laganá. Autoavaliação, prática inovadora para promover o aprendizado. Tecné Episteme y Didaxis: TED, p. 24-31, 2016. Disponível em: https://revistas.pedagogica.edu.co/index.php/TED/article/view/4419 Acesso em 15 mar. 2020.

BACICH, Lilian; NETO, Adolfo Tanzi; TREVISANI, Fernando de Mello. Ensino Híbrido: personalização e tecnologia na educação. Porto Alegre: Penso. 2015. p. 270.

BECKER, Deise; MAUER, Jocimara; EMER, Simone; BEHAR, Patrícia A.; ASSUMPÇÃO, Sandra Maria. O uso de objetos de aprendizagem com alunos surdos no ensino superior. In: Brazilian Symposium on Computers in Education (Simpósio Brasileiro de Informática na Educação-SBIE). 2014. Dourados: Mato Grosso do Sul. v. 25, n 1, p. 832. Disponível em: https://br-ie.org/pub/index.php/sbie/article/view/3017 Acesso em: 18 ago. 2019.

BRASIL. Ministério da Educação. Base Nacional Comum Curricular. Brasília: MEC, 2017. Disponível em: http://basenacionalcomum.mec.gov.br/abase/\#introducao. Acesso em: 28 set. 2020.

BRASIL. Ministério da Educação. Lei de Diretrizes e Bases da Educação Nacional. LDB 9.394, de 20 de dezembro de 1996. Brasília. 1996. Disponível em: http://www.planalto.gov.br/ccivil_03/Leis/L9394.htm. Acesso em: 28 jul. 2019.

BRASIL. Lei Federal n. 10.436, de 24 de abril de 2002. Dispõe sobre a Língua Brasileira de Sinais - Libras e dá outras providências. Brasília, 2002. Disponível em: http://www.planalto.gov.br/ccivil_03/leis/2002/110436.htm. Acesso em: 28 jul. 2019.

BRASIL, Ministério da Educação. Orientações curriculares para o ensino médio. Ciências da natureza, matemática e suas tecnologias. Secretaria de Educação Média e

Tecnológica/MEC, Brasília, 2006. Disponível em: http://portal.mec.gov.br/busca-geral/195secretarias-112877938/seb-educacao-basica-2007048997/13558-politicas-de-ensino-medio.

Acesso em 30 set. 2019.

BRASIL. INEP. Instituto Nacional de Estudos e Pesquisas Educacionais Anisio Teixeira. Ministério da Educação. Relatório Brasil no PISA Versão Preliminar. Relatório Nacional. Brasília, 2019. Disponível em: http://portal.inep.gov.br/acoes-internacionais/pisa/resultados Acesso em 16 mar. 2020.

FERNANDES, Sueli. Quanto ao aprendizado da modalidade escrita do português como segunda língua. In: Educação de surdos. 2a . ed. Curitiba: InterSaberes, 2012. p. 111-120.

FERREIRA, Graça Regina Armond Matias.; PEREIRA, Sandra Lúcia Pita de Oliveira. O. Uso pedagógico de jogos digitais em ambientes educativos: um estudo de caso com o jogo Calangos no Ensino de Biologia. In: CONGRESSO INTERNACIONAL ABED DE EDUCAÇÃO A DISTÂNCIA (CIAEAD), 19. 2013. Salvador.

FIGUEIREDO, Jospe Eduardo M.; SILVA, André Souza da; WERNECK, Vera Maria B.; COSTA, Rosa Maria E. Moreira da. Sim-Colmeia: Ambiente de simulação da dinâmica populacional de uma colmeia para o ensino de Biologia. In: Brazilian Symposium on Computers in Education (Simpósio Brasileiro de Informática na Educação-SBIE). 2012. 
Disponível em: https://www.br-ie.org/pub/index.php/sbie/article/view/1616 Acesso em: 09 set. 2019.

FONSECA, Sueli Aparecida Ramos da Silva; SHITSUKA Ricardo; RISEMBERG, Rabbith Ive Carolina Shitsuka; SHITSUKA, Dorlivete Moreira. Biologia no Ensino Médio: Os saberes e o fazer pedagógico com uso de recursos tecnológicos. Biota Amazônia (Biote Amazonie, Biota Amazonia, Amazonian Biota) v. 4, n. 1, p. 119-125, 2014. https://periodicos.unifap.br/index.php/biota/article/view/840 Acesso em 5 ago. 2019.

FREITAS, Sirley Leite; NINKE, Angélica; MIGUEL, José Carlos. Concepções de avaliação e práticas avaliativas: desafios e possibilidades. EDUCA-Revista Multidisciplinar em Educação, v. 5, n. 11, p. 3-19, 2018. Disponível em: http://200.129.142.19/index.php/EDUCA/article/view/3168 Acesso em 14 mar. 2020.

GENEROSO, Ana Amélia Pardini; NETO, João Coelho, REINEHR, Sheila, MALUCELLI, Andreia. Abordagem Qualitativa do uso das TDIC na Educação Básica. In: Anais do Workshop de Informática na Escola, v. 1, n. 1, p. 230. 2013. Disponível em: https://brie.org/pub/index.php/wie/article/view/2600 Acesso em 18 mar. 2020.

HOFFMAN, Jussara. Avaliação: mito e desafio uma perspectiva construtivista. 44 ed. Porto Alegre: Mediação, 2014a.

JUNIOR, João Batista Bottentuit. O aplicativo Kahoot na educação: verificando os conhecimentos dos alunos em tempo real. In: Livro de atas X Conferência Internacional de TIC na Educação-Clallenges. 2017. p. 1587-1602.

KRASILCHIK, Myriam. Ensino de ciências e a formação do cidadão. Em Aberto, v. 7, n. 40, 2007.

KRASILCHIK, Myriam. Prática de ensino de Biologia. $4^{a}$ ed. São Paulo: Editora da Universidade de São Paulo. 2008.

LOPES, Leticia Azambuja; LOPES, Paulo Tadeu Campos. Explorando o Pokémon GO como modelo para o ensino de Biologia. Acta Scientiae, v. 19, n. 3, 2017. Disponível em: http://www.periodicos.ulbra.br/index.php/acta/article/view/3105 Acesso em: 19 ago. 2019.

LUCKESI, Cipriano Carlos. Avaliação da aprendizagem na escola: reelaborando conceitos e recriando a prática. Salvador: Malabares Comunicação e Eventos, 2003.

MARTINHO, Tânia; POMBO, Lúcia. Potencialidades das TIC no ensino das Ciências Naturais-um estudo de caso. Revista Electrónica de Enseñanza de las Ciencias, v. 8, n. 2, p. 527-538, 2009.

MERCADO, Luís Paulo Leopoldo; SILVA, Alex Melo da; GRACINDO, Heloisa Barbosa Rocha. Utilização didática de objetos digitais de aprendizagem na educação on-line. EccoS Revista científica. v. 10, n. 1, p. 105-123, 2008.

NICHELE, Aline Grunewald; SCHLEMMER, Eliane; RAMOS, Adriana de Farias. QR codes na educação em química. RENOTE-Revista Novas Tecnologias na Educação, v. 13, n. 2, 
2015. Disponível em: https://www.seer.ufrgs.br/renote/article/view/61425 Acesso em 21 mar. 2020.

PEIXOTO, Renata Castelo Algumas considerações sobre a interface entre a Língua Brasileira de Sinais (LIBRAS) e a Língua Portuguesa na construção inicial da escrita pela criança surda. Caderno Cedes, Campinas, v. 26, n. 69, p. 205-229. 2006.

PEREIRA, Fábio Rodrigue; ARRUDA, Guilherme Barros. Material didático no ensino de geografia para surdos. Revista de Geografia do Colégio Pedro II, v. 3, n. 5, p. 103-110, 2017. Disponível em: http://cp2.gov.br/ojs/index.php/GIRAMUNDO/article/view/1358 Acesso em 13 mar. 2020.

PIEMONTE, Mariana da Rocha, WANDERER, Carla, RIOS, Flávia Sant'Anna, FARIAS, Édison Luiz Prisco. Dissecação de coxa e perna de galinha e uso de cards histológicos como ferramenta metodológica para o estudo de biologia tecidual. Revista Gestão \& Saúde. 2019; 20(2):1-13. Disponível em: http://www.herrero.com.br/revista/20/02. Acesso em 12 mar. 2020.

QUADROS, Ronice Müller. O 'Bi' em bilinguismos na educação de surdos. In: FERNANDES, Eulália (Org). Surdez e bilinguismo. $4^{a}$ Ed. 104 p. Porto Alegre: Mediação, 2011.

RAMOS, Daniela Karine; SANTOS, Juline dos; ANASTÁCIO, Bruna Santa. Wiki como estratégia para produção e colaboração na organização de um júri simulado: experiência na oferta de uma disciplina a distância no Brasil. PRISMA. COM, (40), 144-152. 2019. Disponível em https://ojs.letras.up.pt/ojs/index.php/prismacom/article/view/6536 Acesso em 15 mar. 2020.

ROALD, Ingvild; Norwegian deaf teachers' reflections on their science education: implications for instruction. Journal of Deaf Studies and Deaf Education, v. 7, n. 1, p. 5773, 2002. Disponível em: https://academic.oup.com/jdsde/article/7/1/57/742979 Acesso em 14 mar. 2020.

ROCHA, Luiz Renato Martins; MORETTI, Alexandra Renata; COSTA, Priscila Caroza Frasson; COSTA, Fabiano Gonçalves. Educação de surdos: relato de uma experiência inclusiva para o ensino de ciências e biologia. Revista Educação Especial, v. 28, n. 52, 2015. Disponível em: https://www.redalyc.org/articulo.oa?id=313138442010 Acesso em 02 jul. 2019.

ROTHSTEIN, June Maria Emeline Mesquita do Barreiro; SANTOS, Maria da Glória Gonçalves. ENSINO HÍBRIDO: Enlace de Experiências Pedagógicas em Metodologias Ativas. Revista Olhares, v. 1, n. 7, 2017. Disponível em:

http://revistas.unijorge.edu.br/Portal/index.php/Olhares/article/view/42Acesso em 12 jan. 2019.

SCHIMIGUEL, Juliano; FERNANDES, Rafael Francisco; FRANÇA, Léa dos Santos. Desenvolvimento de objetos de aprendizagem na forma de jogos para ensino de libras. Sintec-IV Simpósio Nacional de Ensino de Ciência e Tecnologia, 2014. 
SILVA, Alice Teixeira da; BEZERRA, Maria Lusia de Morais Belo, BALTAR, Solma Lúcia Souto Maior de Araújo; SILVA, Neuza Pereira de Oliveira. Contribuições da atividade prática para o ensino e a aprendizagem de biologia: experiência com a extração do DNA do morango. In: Anais do Congresso de Inovação Pedagógica em Arapiraca. 2015. Disponível em https://www.seer.ufal.br/index.php/cipar/article/view/1886 Acesso em 15 jan. 2019.

SILVA, João Batista da; ANDRADE, Maria Helena, OLIVEIRA, Rannyelly Rodrigues de; SALES, Gilvandenys Leite; ALVES, Francisco Regis Vieira. Tecnologias digitais e metodologias ativas na escola: o contributo do Kahoot para gamificar a sala de aula. Revista Thema, 15(2), 780-791. 2018. Disponível em: http://revistathema.ifsul.edu.br/index.php/thema/article/view/838 Acesso em 15 mar. 2020.

SCHNEIDER, Eduarda Maria; FUJII, Rosangela Araujo Xavier; CORAZZA, Maria Júlia. Pesquisas quali-quantitativas: contribuições para a pesquisa em ensino de ciências. Revista Pesquisa Qualitativa, v. 5, n. 9, p. 569-584, 2017. Disponível em: https://editora.sepq.org.br/index.php/rpq/article/view/157 Acesso em 10 mar. 2020.

SOARES, Raquel Madeira; BAIOTTO, Cléia Rosani. Aulas práticas de biologia: suas aplicações e o contraponto desta prática. Di@ logus, v. 4, n. 2, p. 53-68, 2015. Disponível em: http://revistaeletronica.unicruz.edu.br/index.php/Dialogus/article/view/2688 Acesso em: 10 mar. 2020.

SOLINO, Ana Paula; FERRAZ, Arthur Tadeu; SASSERON, Lúcia Helena. Ensino por investigação como abordagem didática: desenvolvimento de práticas científicas escolares. In: XXI Simpósio Nacional de Ensino de Física, p. 1-6, 2015.

SPINARDI, Janine Donato; BOTH, Ivo José. Blended learning: o ensino híbrido e a avaliação da aprendizagem no ensino superior. Boletim Técnico do Senac, v. 44, n. 1, 2018.

Disponível em: https://www.bts.senac.br/bts/article/view/648 Acesso em 10 jan. 2019.

STYLIANOUDAKIS, Marília; BÔAVENTURA, Ricardo Soares. QR Codes como Ferramenta Interativa e Facilitadora do Processo de Ensino e Aprendizagem. Olhares \& Trilhas, v. 20, n. 1, p. 270-276, 2018. Disponível em http://www.seer.ufu.br/index.php/olharesetrilhas/article/view/41971 Acesso em 24 fev. 2020.

TRIVELATO, Silvia L. Frateschi; TONIDANDEL, Sandra M. Rudella. Ensino por investigação: eixos organizadores para sequências de ensino de biologia. Ensaio Pesquisa em Educação em Ciências, v. 17, 2015. Disponível em https://www.scielo.br/scielo.php?pid=S198321172015000400097\&script=sci_arttext\&tlng=pt Acesso em 7 nov. 2019.

VASCONCELLOS, Roberta Flávia Ribeiro Rolando; MELANI, Aniceta da Conceição Antunes de Brito. Um estudo da utilização do blog bioartes para a disciplina de biologia. Revista Magistro, v. 2, n. 16, 2017. Disponível em: http://publicacoes.unigranrio.edu.br/index.php/magistro/article/view/4852 Acesso em: 18 ago. 2019.

Recebido em: 31 de julho de 2020.

Aprovado em: 19 de outubro de 2020. 